\title{
Multicystic dysplastic kidney with severe abdominal obstruction signs - case reports and management of children
}

\author{
Justyna Czubilińska-Łada', Aleksandra Gliwińska², Anna Szymańska1', Jakub Behrendt', \\ Lucyna Nowak-Borzęcka ${ }^{3}$, Monika Kulig-Kulesza ${ }^{4}$, Maria Szczepańska ${ }^{5}$

\begin{abstract}
'Chair and Department of Neonatal Intensive Care, Faculty of Medical Sciences in Zabrze, Medical University of Silesia in Katowice, Poland

${ }^{2}$ Department of Paediatric Nephrology with Dialysis Division for Children, Independent Public Clinical Hospital No. 1, Zabrze, Poland

${ }^{3}$ Department of Neonatal Pathology, Multi-Specialist Hospital, Gliwice, Poland

${ }^{4}$ Department of Radiology, Faculty of Medical Sciences in Zabrze, Medical University of Silesia in Katowice, Poland ${ }^{5}$ Chair and Department of Paediatrics, Faculty of Medical Sciences in Zabrze, Medical University of Silesia in Katowice,
\end{abstract} \\ Poland
}

\section{ABSTRACT}

Introduction: Multicystic dysplastic kidney (MCDK) is a relatively common developmental abnormality of the urinary tract. In most cases, it is an asymptomatic disease and rarely leads to problems emerging from the pressing effect of large MCDK kidneys on the adjacent organs. Nowadays, surgical intervention has mostly been replaced by a non-invasive approach with long-term follow-up.

Aim of the study: Analysis of the diagnostic process, patients' clinical condition, treatment, and follow-up in neonatal patients with extreme MCDK.

Material and methods: Retrospective analysis of medical records of four infants with extreme MCDK, who were hospitalised in the Department of Intensive Therapy and Neonatal Pathology in Independent Public Clinical Hospital No. 1 in Zabrze in 2014-2019. The study also includes data from an out-patient nephrological unit, where infants are checked up by paediatric nephrologists every 6 to 12 months.

Results: All four patients involved in this study were diagnosed during the prenatal period. After birth, the initial diagnosis was confirmed by ultrasound, X-ray, computed tomography (CT), magnetic resonance imaging (MRI), and/or scintigraphy. All patients in their neonatal period presented the symptoms caused by the pressing effect of the large size of MCDK kidneys, such as abdominal or flank discomfort, digestive disturbances, or respiratory distress. The life-threatening clinical condition of two of our patients led to surgical intervention, which significantly improved their life functions. The stable clinical condition of another two infants enabled a non-invasive approach. All four infants still remain under long-term follow-up. They are not afflicted with any problems emerging from the urinary tract and they do not require any pharmacological treatment.

Conclusions: Despite the currently proposed non-invasive approach to MCDK, there are cases when a nephrectomy should be a considered, especially regarding patients with extreme-sized kidneys.

KEY WORDS:

nephrectomy, multicystic dysplastic kidney, urinary tract malformations, renal imaging, non-invasive approach.

\section{ADDRESS FOR CORRESPONDENCE:}

Maria Szczepańska, Chair and Department of Paediatrics, Faculty of Medical Sciences in Zabrze, Medical University of Silesia in Katowice, 13/15 3 Maja St., 41-800 Zabrze, Poland, ORCID: 0000-0002-6772-1983, e-mail: szczep57@poczta.onet.pl 


\section{INTRODUCTION}

Multicystic dysplastic kidney (MCDK) is one of the most commonly identified urinary tract anomalies, the overall incidence of which is approximately 1 in 4300 live births. It is one of the most frequent causes of a palpable abdominal mass in the neonatal period and is the most common cystic malformation of kidneys in infancy [1-3].

There are two leading theories explaining the aetiology of MCDK. The first one suggests that MCDK results from a failure of differentiation of the mesenchymal metanephros and epithelial cells of the ureteral bud, although this view has been questioned because sometimes kidney in MCDK contains some functional renal tissue. An alternative theory suggests that the alteration of the nephrogenesis arises from an impaired foetal urine flow in the early development, which is confirmed by the common finding that each MCDK is generally attached to a non-functioning or atretic ureter [4-6].

The picture of MCDK is characterised by a grapelike cluster of cysts, usually with no identifiable normal renal parenchyma. Currently, it is one of the most commonly detected anomalies on prenatal ultrasound, and its diagnosis has increased in the past 20 years due to the widespread use of antenatal and postnatal ultrasonography. MCDK usually occurs unilaterally, predominantly in males, and coexists with other urinary tract malformations such as ureteral dilation, ureterovesical stenosis, ureterocele, and ureteral valves. Thus, a more detailed postnatal follow-up is required as a consequence of prenatal detection of MCDK $[3,7,8]$.

In the natural course of unilateral MCDK, involution of the afflicted kidney is accompanied by compensatory contralateral hypertrophy. Most infants (about 90\%) develop contralateral hypertrophy at the age of three years, which is considered as a good indicator of further kidney function. Unilateral MCDK without contralateral compensatory hypertrophy is regarded as a risk factor for future renal insufficiency and requires imaging follow-up $[9,10]$.

Renal ultrasound is a natural imaging choice for the follow-up of MCDK patients. Although there are some reports about using fetal magnetic resonance imaging (MRI) for the diagnosis of urinary tract anomalies, there is no confirmation about its clinical value [8]. An alternative approach includes renal scintigraphy, which provides additional information about the current renal function and can be used to confirm a diagnosis of MCDK and accompanying urinary tract malformations. Some authors believe that constant improvement of the renal ultrasound technique is sufficient and there is no need for further confirmation of the MCDK diagnosis by nuclear medicine scan in patients with normal bladder ultrasound image [11]. The first-line imaging for the diagnosis of contralateral vesicoureteral reflux (VUR), which is the most frequent abnormality, occurring in 5 to $43 \%$ of patients with unilateral MCDK, is voiding cystourethrog- raphy (VCUG). However, the necessity of routine VCUG is still debated in the literature [12-14].

Until recently, MCDK was generally managed by nephrectomy to avoid complications, such as urinary tract infections, hypertension, or malignant transformation. Currently, the non-invasive protocol has been appointed due to recent studies showing high rates of spontaneous partial or complete involution, low risk of hypertension, and neoplasia. Long-term follow-up of children with MCDK by ultrasound monitoring seems to be the firstline management [15-18].

The most common means of identification of MCDK is ultrasonography or another imaging method. However, there are rare cases when surgical intervention is required, and the diagnosis is made during the surgery itself [19].

This study describes the case studies of four infant patients, in whom the process of diagnosis, treatment, and follow-up was difficult to manage due to the extraordinary dimensions of the affected kidneys.

\section{MATERIAL AND METHODS}

We reviewed retrospectively the medical charts of four patients (two males and two females) with extreme MCDK hospitalised in the neonatal period in the Department of Intensive Therapy and Neonatal Pathology in Zabrze in the years 2014-2019. All patients were followed-up by experienced paediatric nephrologists.

The diagnosis of MCDK was given after prenatal ultrasound findings in all four patients, based on the detected features of multiplied various-sized cysts located in the kidney with no visible parenchymal tissue. In order to extend the diagnosis, additional imaging was performed after birth, including abdominal ultrasound (US) (all patients), abdominal X-ray (three patients), CT scan (one patient), MRI scan (one patient), renal scintigraphy (three patients), and voiding cystourethrogram (two patients). Alongside the postnatal imaging findings we simultaneously evaluated the following clinical parameters: gender, gestational age, condition after birth, APGAR score, renal function tests (serum creatinine and urea level $72 \mathrm{~h}$ after birth), cancer risk factors, MCDK side, occurrence of other urological and non-urological abnormalities and dysfunctions, modelling effect on another organs, deviations in physical examination, hypertension, and recurrent urinary tract infections.

Senior staff consisting of experienced neonatologists, paediatric nephrologists, urologists, and paediatric surgeons decided that two of our patients required surgical interventions in the neonatal period. The remaining two patients were treated with a conservative approach.

Since being discharged from the hospital all four patients are being checked up for general development, weight, height, concomitant illnesses, or alterations during the control visits every 6-12 months. Abdominal 
ultrasound examination and arterial blood pressure are also verified the same as serum creatinine and urea level, acid-base balance parameters, blood morphology, and urine analysis.

\section{RESULTS}

We reviewed the process of diagnosis, treatment, and follow-up in neonates with unilateral MCDK, in whom affected kidneys were extremely large, thus modelling other adjacent organs (left kidneys in three cases and right kidney in one case). The characteristics of enrolled patients are presented in Table 1. The diagnosis was made in the prenatal period using the maternal sonography for foetal screening in all four cases.

Two infants were born in the full term. One of them was in good condition, while the other required oxygen therapy for a couple of hours after birth. Two more infants were born preterm, and both required additional support.

Palpable masses were discovered during the physical examination of the abdomen in all four infants, although they were clearly palpable in only three of them. All infants presented digestive tract symptoms, such as disturbance of passage, stomach alimentary residuals, decreased appetite, and weakened suction reflex.

A differential diagnosis was performed to prove a connection between cystic structure and the urinary tract. Even though this imaging confirmed the large-size polycystic character of masses and their contribution to relocating other organs, it did not reveal clearly their origin in all of our cases.

The first patient's renal scintigraphy revealed no function of the left kidney and normal function of the right one. The performed VCUG was normal. Because of the disturbance in the functioning of the alimentary tract and bilateral pneumothorax in parabasal parts of lungs, surgical intervention was necessary. The initial procedure was decompression of the cysts by using a nephrostomy catheter. Even though the sterile fluid was evacuated, the US imaging revealed no dimensional change of the cysts. Because of the clinical condition, the patient was qualified for the left-sided nephrectomy by laparoscopic method, which finally confirmed the MCDK diagnosis based on the macroscopic image and histopathological examination (Fig. 1).

The second patient's MRI scan revealed compensatory hypertrophy of the right kidney and multicystic forms mainly on the right side of the abdomen, which was in favour of the MCDK diagnosis with crossed ectopia. Due to the bad clinical condition of the patient, including decreased appetite, distended stomach, and weakened suction reflect, the decision to perform left-sided nephrectomy was undertaken. This procedure led to the improvement of the patient's clinical condition and confirmed the diagnosis of MCDK.
The third patient had early syndromes of digestive tract disability in her early days; however, they gradually disappeared, leading to a conservative approach instead of surgical intervention. At the age of one year, a performed VCUG did not reveal any abnormalities in the lower urinary tract. Five months later renal scintigraphy was performed revealing absent function in the affected right kidney and normal renal excretion on the left side. Until now, only one episode of the urinary tract infection was noted in this child. Control abdominal ultrasound revealed the stationary size of the affected kidney.

The fourth patient was diagnosed with MCDK based on an abdominal ultrasound. Initial problems with the disturbed passage of the digestive tract could be due either to infection or patent ductus arteriosus (PDA). After the successful pharmacological closure of PDA and the reduction of the inflammatory parameters, there were no alarming symptoms from the urinary tract. The decision to use a non-surgical approach was made. During the follow-up, no complications arising from left-sided MCDK were detected. The ultrasound image revealed that the afflicted kidney started to involute. Renal scintigraphy is planned in the future.

Follow-up data presented in Table 2 were collected from all patients, who are now at the age between 5 and 58 months. During follow-up, the first patient was hospitalised because of performed adenotomy, the third patient required surgical intervention due to ovarian torsion on the opposite side to MCDK kidney, and the fourth patient was hospitalised due to respiratory tract infections. All children have normal general development, they do not suffer from any problems from the urinary tract, and they do not require any permanent drug treatment.

\section{DISCUSSION}

Before the widespread use of maternal sonography for foetal screening, most of the diagnosed MCDK cases were large palpable masses identified during the physical examination of a newborn. At that time detecting these abnormalities demanded nephrectomy as a primary treatment, which was considered as the safest therapy to avoid further complications, such as recurrent urinary tract infections, hypertension, and neoplasia [15, 20]. Several studies showed that the prevalence of malignant transformation and hypertension among MCDK patients reflects the occurrence in the general paediatric population $[2,17,18$, 21-24]. Moreover, a prospective study published in 2004 by Rabelo et al. demonstrated that complete or partial involution is the most frequently observed course of MCDK. In that study 43 children with MCDK diagnosed by ultrasound scans were involved. The average length of the MCDK was $62 \mathrm{~mm}$ (range 18-148 mm). Follow-up lasted for 12-156 months and showed partial involution of the MCDK in $70 \%$ of cases, complete involution in 19\%, and stable size in $11 \%$ [22]. A number of studies have found 
TABLE 1. Characteristics of patients with multicystic dysplastic kidney (MCDK)

\begin{tabular}{|c|c|c|c|c|}
\hline Characteristic & Patient 1 & Patient 2 & Patient 3 & Patient 4 \\
\hline Gender & Male & Male & Female & Female \\
\hline Gestational age & Full-term & Pre-term (33 weeks) & Pre-term (35 weeks) & Full-term \\
\hline Condition after birth & Normal & $\begin{array}{l}\text { Average, required } \\
\text { ventilator support }\end{array}$ & $\begin{array}{l}\text { Average, required } \\
\text { external stimulation }\end{array}$ & $\begin{array}{l}\text { Average, required oxygen } \\
\text { therapy for few hours }\end{array}$ \\
\hline Antenatal diagnosis & Yes & Yes & Yes & Yes \\
\hline MCDK side & Left & Left & Right & Left \\
\hline $\begin{array}{l}\text { Physical examination } \\
\text { of abdomen }\end{array}$ & $\begin{array}{l}\text { Palpable masses and } \\
\text { quiet peristalsis on the } \\
\text { left side of abdomen }\end{array}$ & $\begin{array}{l}\text { Palpable masses in both } \\
\text { sides of abdomen }\end{array}$ & $\begin{array}{l}\text { Poorly detectable } \\
\text { masses on the right } \\
\text { side of abdomen }\end{array}$ & Palpable masses \\
\hline Urinary tract infections & Once in neonatal period & No & $\begin{array}{l}\text { Once in third month } \\
\text { of life }\end{array}$ & No \\
\hline $\begin{array}{l}\text { Other urological } \\
\text { affections }\end{array}$ & No & No & Small cyst in left kidney & No \\
\hline $\begin{array}{l}\text { Syndromes from } \\
\text { digestive tract }\end{array}$ & $\begin{array}{l}\text { Alimentary residuals, } \\
\text { blood appearing } \\
\text { in the stools }\end{array}$ & $\begin{array}{c}\text { Decreased appetite, } \\
\text { weakened suction reflex }\end{array}$ & $\begin{array}{c}\text { Decreased appetite, } \\
\text { weakened suction } \\
\text { reflex }\end{array}$ & $\begin{array}{l}\text { Disturbed passage of } \\
\text { digestive tract }\end{array}$ \\
\hline $\begin{array}{l}\text { Non-urological } \\
\text { dysfunctions }\end{array}$ & No & No & No & $\begin{array}{l}\text { Patent ductus arteriosus, } \\
\text { dysmorphic facial features }\end{array}$ \\
\hline Size of the cysts cluster & $92 \times 66 \times 100 \mathrm{~mm}(\mathrm{CT})$ & $57 \times 97 \times 100 \mathrm{~mm}(\mathrm{MRI})$ & $67 \times 38 \mathrm{~mm}$ (US) & $80 \times 55 \mathrm{~mm}(\mathrm{US})$ \\
\hline $\begin{array}{l}\text { Modelling effects on } \\
\text { another organs }\end{array}$ & $\begin{array}{l}\text { Revealed in CT scan } \\
\text { relocation of intestines } \\
\text { to the opposite side, } \\
\text { modelling the pancreas, } \\
\text { stomach, spleen, } \\
\text { mesenteric arteries, } \\
\text { urinary bladder. Bilateral } \\
\text { pneumothorax in } \\
\text { parabasal parts }\end{array}$ & $\begin{array}{c}\text { Revealed in MRI } \\
\text { modelling neighbouring } \\
\text { structures, especially the } \\
\text { pancreas, liver, spleen, } \\
\text { stomach, intestines, } \\
\text { right kidney }\end{array}$ & No & No \\
\hline Scintigraphy & $\begin{array}{l}\text { No detected function } \\
\text { of left kidney. Normal } \\
\text { function of right kidney }\end{array}$ & - & $\begin{array}{l}\text { No detected function } \\
\text { of right kidney. Normal } \\
\text { function of left kidney }\end{array}$ & Planned \\
\hline \multicolumn{5}{|c|}{ Renal function tests $72 \mathrm{~h}$ after birth } \\
\hline $\begin{array}{l}\text { Creatinine serum level } \\
(\mu \mathrm{mol} / \mathrm{l})\end{array}$ & 64 & 68 & 51 & 87 \\
\hline $\mathrm{eGFR}\left(\mathrm{ml} / \mathrm{min} / 1.73 \mathrm{~m}^{2}\right)$ & 36.1 & 19.3 & 28.0 & 22.9 \\
\hline Urea serum level $(\mathrm{mmol} / \mathrm{l})$ & 6.3 & 11.3 & - & - \\
\hline \multicolumn{5}{|l|}{ Cancer risk factors } \\
\hline $\operatorname{AFP}(\mathrm{ng} / \mathrm{ml})$ & 740.3 & 488.6 & - & - \\
\hline CEA (ng/ml) & 6.98 & - & - & - \\
\hline$\beta$-hCG (mlU/ml) & 0.458 & - & - & - \\
\hline \multicolumn{5}{|l|}{ Chirurgical intervention } \\
\hline $\begin{array}{l}\text { Laparoscopic } \\
\text { nephrectomy }\end{array}$ & $\begin{array}{l}\text { In neonatal period - } \\
\text { firstly decompression } \\
\text { of cysts by using } \\
\text { nephrostomy tube. } \\
\text { Because of lack of } \\
\text { contenting effect } \\
\text { nephrectomy was needed }\end{array}$ & In neonatal period & - & - \\
\hline $\begin{array}{l}\text { Histopathological } \\
\text { examination }\end{array}$ & $\begin{array}{l}\text { Validated diagnosis } \\
\text { of MCDK }\end{array}$ & $\begin{array}{l}\text { Validated diagnosis } \\
\text { of MCDK }\end{array}$ & - & - \\
\hline
\end{tabular}

CT - computed tomography, MRI - magnetic resonance imaging, US - ultrasound, eGFR - estimated glomerular filtration rate, according to new Schwartz formula, AFP - alpha-fetoprotein, CEA - carcinoembryonic antigen 
that initially smaller MCDKs are more likely to involute at an earlier age in comparison to larger MCDKs $[25,26]$.

MCDK is usually asymptomatic; however, large size of abnormal kidneys can cause a pressure effect on adjacent organs, manifested by abdominal or flank discomfort, disorders in the digestive tract, or respiratory distress. These symptoms of abdominal compartment syndrome could be explained by the constricting effect of large-size cysts situated in dysplastic kidneys, which can also lead to respiratory problems caused by consecutive diaphragmatic elevation. When those disturbances are distinctly connected with the pressing effect of MCDK kidney, the abnormal kidney should be removed $[1,27,28]$. In our study, among four patients with enormous size of the affected kidney, two infants required early nephrectomy during their hospitalisation in the Department of Neonatal Pathology. This procedure enabled clinical stabilisation of newborns and improved functioning of the urinary tract and other organs. On the other hand, in these two patients, the diagnosis of MCDK was confirmed after surgical intervention, based on the macroscopic and microscopic view. Previously accomplished imaging did not give assured answers about the origin of cystic masses or its connection with the urinary tract, and it could not exclude malignant proliferation.

Long-term follow-up appears to be widespread, proceeding in both conservative and surgical approaches; however, no universally accepted management protocol has been elaborated. Abdominal ultrasound is a widely used imaging method for monitoring of growth or involution of both cystic and contralateral kidneys, as well as identifying other urinary tract anomalies. Other investigations widely used during follow-up are blood pressure control, urine analysis, and measurement of creatinine, urea, and electrolytes serum levels. More diversified imaging techniques containing VCUG or renal scintigraphy are considered individually.

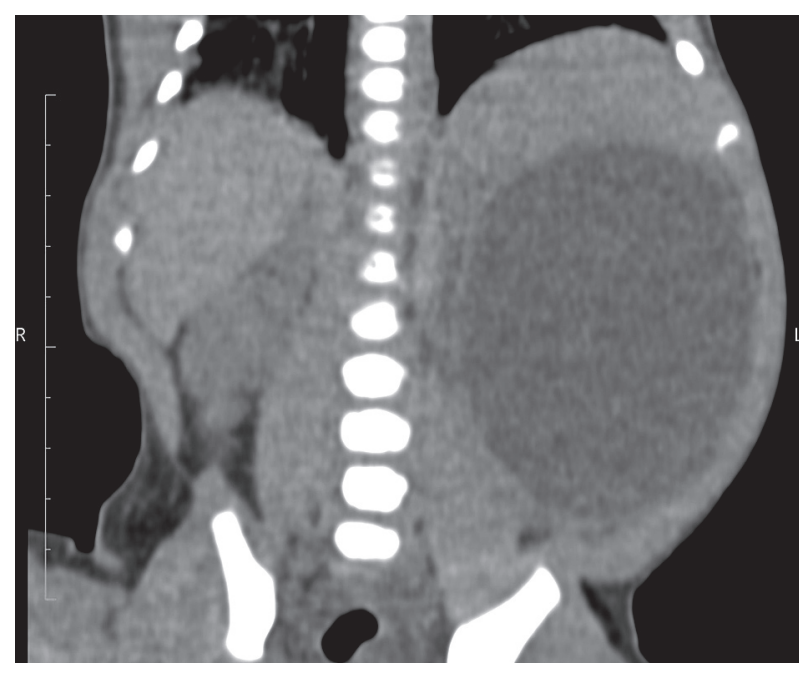

FIGURE 1. First patient's computed tomography scan

In recent years the majority of studies have found a non-invasive conservative approach with long-term ultrasound follow-up as the most appropriate treatment $[17,18,21,24,25,29]$. The retrospective cohort study performed by Brown et al. revealed a decreasing trend in using an invasive approach for MCDK patients between January 2006 and September 2015. Meanwhile, the percentage of minimally invasive nephrectomies (laparoscopic non-robotic and robotic) among all performed nephrectomies in this period increased significantly (from $8 \%$ in 2006 to $29 \%$ in 2015 ) [ 30,31 ]. No universal indications have been established for nephrectomy in unilateral MCDK patients, except for a few clinical indications, such as: uncontrolled blood pressure despite the use of pharmacological treatment, ultrasound image suggesting the presence of malignant proliferation, and an enlarging renal mass pressing adjacent organs $[2,28]$. The last one was the reason why it was decided to perform surgery on our patients. The size of the affected kidney that should determine the need for a nephrectomy is discussed. Some

TABLE 2. Follow-up data

\begin{tabular}{|c|c|c|c|c|}
\hline Characteristic & Patient 1 & Patient 2 & Patient 3 & Patient 4 \\
\hline General development & Normal & Normal & Normal & Normal \\
\hline Actual age & 5 years 3 months & 2 years 3 months & 2 years 4 months & 9 months \\
\hline Weight & $>97 p c$ & $10-25 p c$ & $<3 p c$ & $75 p c$ \\
\hline Height & $>97 p c$ & $3 p c$ & $<3 p c$ & $75 p c$ \\
\hline Hospitalisations & Adenotomy at the age of 4 & No & $\begin{array}{l}\text { At the age of } 3 \text { months urinary } \\
\text { tract infection; at the age of } \\
4 \text { months left-sided ovarian } \\
\text { torsion - surgical intervention }\end{array}$ & $\begin{array}{l}\text { Respiratory system } \\
\text { infections }\end{array}$ \\
\hline $\begin{array}{l}\text { Pharmacological } \\
\text { medication }\end{array}$ & No & No & No & No \\
\hline Hypertension & First 5 months after birth & No & First 2 weeks after birth & No \\
\hline $\begin{array}{l}\text { Urinary tract } \\
\text { condition }\end{array}$ & Normal & $\begin{array}{l}\text { Compensatory } \\
\text { hypertrophy of the } \\
\text { remaining kidney }\end{array}$ & $\begin{array}{l}\text { Normal, stable size of the } \\
\text { affected kidney }\end{array}$ & $\begin{array}{l}\text { Normal, ultrasound } \\
\text { present involution } \\
\text { of affected kidney }\end{array}$ \\
\hline
\end{tabular}


clinics present the approach that nephrectomy is the best treatment for children if the size of a cluster is $\geq 5 \mathrm{~cm}$ in the first year of life or $<5 \mathrm{~cm}$ with no signs of regression during follow-up [19]. The currently offered laparoscopic surgery instead of open surgery is considered as a safe solution in justified cases. In addition, there are many benefits of performing the procedure, such as exemption from regular check-up visits [30]. An additional advantage is the complete removal of residual renal tissue, while a conservative approach has been proven to reveal the presence of atrophic renal tissue despite the apparent total evolution in the US image [32]. Yamataka et al. presented a retrospective study comparing the costs of leading patients with unilateral MCDK after using different therapeutic options. It was concluded that if the observation of the patient lasted longer than five years due to lack of regression, the costs of necessary control visits and imaging were higher than the costs of laparoscopic nephrectomy [33].

In conclusion, although nowadays routine nephrectomy in MCDK is regarded as an inappropriate procedure, surgical intervention is always an option to consider in cases with extreme symptomatic dimensions of MCDK.

\section{DISCLOSURE}

The authors declare no conflict of interest.

\section{REFERENCES}

1. Kara A, Gurgoze MK, Aydin M, et al. Clinical features of children with multicystic dysplastic kidney. Pediatr Int 2018; 60: 750-754.

2. Chang A, Sivananthan D, Nataraja RM, et al. Evidence-based treatment of multicystic dysplastic kidney: a systematic review. J Pediatr Urol 2018; 14: 510-519.

3. Luque-Mialdea R, Martín-Crespo R, Cebrian J, et al. Does the multicystic dysplastic kidney really involute? The role of the retroperitoneoscopic approach. J Pediatr Urol 2007; 3: 48-52.

4. Schreuder MF, Westland R, van Wijk JA. Unilateral multicystic dysplastic kidney: a meta-analysis of observational studies on the incidence, associated urinary tract malformations and the contralateral kidney. Nephrol Dial Transplant 2009; 24: 1810-1818.

5. Woolf AS. Unilateral multicystic dysplastic kidney. Kidney Int 2006; 69: 190-193.

6. Woolf AS, Price KL, Scambler PJ, et al. Evolving concepts in human renal dysplasia. J Am Soc Nephrol 2004; 15: 998-1007.

7. Cardona-Grau D, Kogan BA. Update on Multicystic Dysplastic Kidney. Curr Urol Rep 2015; 16: 67.

8. Ji H, Dong SZ. Magnetic resonance imaging for evaluation of foetal multicystic dysplastic kidney. Eur J Radiol 2018; 108: 128-132.

9. Gaither TW, Patel A, Patel C, et al. Natural History of Contralateral Hypertrophy in Patients with Multicystic Dysplastic Kidneys. J Urol 2018; 199: 280-286.

10. Gimpel C, Avni EF, Breysem L, et al. Imaging of Kidney Cysts and Cystic Kidney Diseases in Children: An International Working Group Consensus Statement. Radiology 2019; 290: 769-782.

11. Whittam BM, Calaway A, Szymanski KM, et al. Ultrasound diagnosis of multicystic dysplastic kidney: is a confirmatory nuclear medicine scan necessary? J Pediatr Urol 2014; 10: 1059-1062.
12. Adamczyk P, Drożdż D, Pańczyk-Tomaszewska M, et al. Postępowanie $\mathrm{z}$ dzieckiem $\mathrm{z}$ podejrzeniem prenatalnym wady wrodzonej układu moczowego streszczenie zaktualizowanych zaleceń Polskiego Towarzystwa Nefrologii dziecięcej. część 2 - zaburzenia rozwojowe miąższu nerkowego. Prz Lek 2019; 76: 208-211.

13. Yamamoto K, Kamei K, Sato M. Necessity of performing voiding cystourethrography for children with unilateral multicystic dysplastic kidney. Pediatr Nephrol 2019; 34: 295-299.

14. Psooy K, Collaboration with the Pediatric Urologists of Canada (PUC). Multicystic dysplastic kidney (MCDK) in the neonate: The role of the urologist. Can Urol Assoc J 2016; 10: 18-24.

15. Okada T, Yoshida H, Matsunaga T, et al. Multicystic dysplastic kidney detected by prenatal ultrasonography: natural history and conservative management. Pediatr Surg Int 2003; 19: 207-210.

16. Singh JK, Kanojia RP, Narasimhan KL. Multicystic Dysplastic Kidney - A Need for Conservative and Long Term Approach. Indian J Pediatr 2009; 76: 809-812.

17. Aslam M, Watson AR. Unilateral multicystic dysplastic kidney: long term outcomes. Arch Dis Child 2006; 91: 820-823.

18. Narchi H. Risk of hypertension with multicystic kidney disease: a systematic review. Arch Dis Child 2005; 90: 921-924.

19. Molina C, Bessa J, Estevanato A, et al. Applicability of Laparoscopic Nephrectomy in the Treatment of Multicystic Dysplastic Kidney: Sorting Out Surgical Indication. Cureus 2018; 10: e2014.

20. Cambio AJ, Evans CP, Kurzrock EA. Non-surgical management of multicystic dysplastic kidney. BJU Int 2008; 101: 804-808.

21. Narchi H. Risk of Wilms tumor with multicystic kidney disease: a systematic review. Arch Dis Child. 2005; 90: 147-149.

22. Rabelo EA, Oliveira EA, Diniz JS, et al. Natural history of multicystic kidney conservatively managed: a prospective study. Pediatr Nephrol 2004; 19: 1102-1107.

23. Tilemis S, Savanelli A, Baltogiannis D, et al. Is the risk of hypertension an indication for prophylactic nephrectomy in patients with unilateral multicystic dysplastic kidney? Scand J Urol Nephrol 2003; 37: 429-432.

24. Hains DS, Bates CM, Ingraham S, et al. Management and etiology of the unilateral multicystic dysplastic kidney: a review. Pediatr Nephrol 2009; 24: 233-241.

25. Eickmeyer AB, Casanova NF, He C, et al. The natural history of the multicystic dysplastic kidney - is limited follow-up warranted? J Pediatr Urol 2014; 10: 655-661.

26. Hayes WN, Watson AR. Unilateral multicystic dysplastic kidney: does initial size matter? Pediatr Nephrol 2012; 27: 1335-1340.

27. Swiatecka-Urban A. Multicystic Renal Dysplasia. Medcape 2016. https://emedicine.medscape.com/article/982560-print

28. Eckoldt F, Woderich R, Wolke S, et al. Follow-up of unilateral multicystic kidney dysplasia after prenatal diagnosis. Matern Fetal Neonatal Med 2003; 14: 177-186.

29. Oliveira EA, Diniz JS, Vilasboas AS, et al. Multicystic dysplastic kidney detected by fetal sonography: conservative management and follow-up. Pediatr Surg Int 2001; 17: 54-57.

30. Steven LC, Li AG, Driver CP, et al. Laparoscopic nephrectomy for unilateral multicystic dysplastic kidney in children. Surg Endosc 2005; 19: 1135-1138.

31. Brown CT, Sebastião YV, McLeod DJ. Trends in surgical management of multicystic dysplastic kidney at USA children's hospitals. J Pediatr Urol 2019; 15: 368-373.

32. Luque-Mialdea R, Martin-Crespo R, Cebrian J, et al. Does the multicystic dysplastic kidney really involute? The role of the retroperitoneoscopic approach. J Pediatr Urol 2007; 3: 48-52.

33. Yamataka A, Satake S, Kaneko K, et al. Outcome and cost analysis of laparoscopic or open surgery versus conservative management for multicystic dysplastic kidney. J Laparoendosc Adv Surg Tech A 2005; 15: 190-193. 